\title{
Transversus abdominis-plane block versus local anesthetic wound infiltration in lower abdominal surgery: a systematic review and meta-analysis of randomized controlled trials
}

Nanze $\mathrm{Yu}^{1+}$, Xiao Long ${ }^{1+}$, Jorge R Lujan-Hernandez ${ }^{2}$, Julien Succar ${ }^{3}$, Xin Xin $^{4}$ and Xiaojun Wang ${ }^{1 *}$

\begin{abstract}
Background: Postoperative pain management is of great importance in perioperative anesthetic care. Transversus abdominis plane (TAP) block has been described as an effective technique to reduce postoperative pain and morphine consumption after open lower abdominal operations. Meanwhile, local anesthetic infiltration (LAl) is also commonly used as a traditional method. However, the effectiveness of these two methods has not been compared before.
\end{abstract}

Methods: A meta-analysis of all relevant randomized controlled trials (RCTs) was conducted to compare the efficacy of single shot TAP block with that of single shot LAI for postoperative analgesia in adults. Major medical databases and trial registries were searched for published and unpublished RCTs. The endpoints include postoperative visual analog scale (VAS) pain score, morphine requirement, and rate of postoperative nausea and vomiting (PONV). For continuous data, weighted mean differences (WMDs) were formulated; for dichotomous data, risk ratios (RR) were calculated. Results were derived using a random-/fixed-effects model with 95\% confidence interval (CI).

Results: Four RCTs, encompassing 96 TAP-block and 100 LAl patients, were included in the final analysis. Patients in the TAP-block group had lower VAS pain scores 24 hours postoperatively compared with the LAl group, both at rest $(\mathrm{WMD}[95 \% \mathrm{Cl}]=-0.67[\mathrm{p}<0.01]$ and with movement $(\mathrm{WMD}=-0.89, \mathrm{p}<0.01)$. There were no significant between-group differences in 24-hour postoperative morphine requirements, the rates if PONV or VAS pain scores at 2 and $4 \mathrm{~h}$ postoperatively.

Conclusion: TAP block and LAI provide comparable short-term postoperative analgesia, but TAP block has better long-lasting effect.

Keywords: Transversus abdominis plane block, Local anesthetic infiltration, Postoperative analgesia, Meta-analysis

\section{Background}

Acute postoperative pain is a common problem encountered not only by pain specialists, but also by all medical professionals in everyday practice [1]. Pain management is an important aspect of perioperative anesthetic care, while whether acute postoperative pain control affects surgical outcomes remains controversial [2]. There is

\footnotetext{
* Correspondence: xjwang100@hotmail.com

${ }^{\dagger}$ Equal contributors

'Division of Plastic Surgery, Peking Union Medical College Hospital, Peking Union Medical College, Chinese Academy of Medical Science, No.1 Shuaifuyuan, Wangfujing, Dongcheng District, Beijing 100730, China Full list of author information is available at the end of the article
}

general agreement that it is a major reason for primary care consultation and a cause of prolonged hospital stays and patient dissatisfaction [3].

Transversus abdominis plane (TAP) block, first described by Kuppuvelumani et al. in 1993 [4] and formally documented by Rafi in 2001 [5], is used for the management of surgical abdominal pain by injecting local anesthesia into the plane between the internal oblique and transversus abdominis muscle [5,6]. TAP-block technique has been shown to be a safe and effective postoperative adjunct analgesia method in a variety of general $[7,8]$, gynecological [9-11], urological [12], plastic [13,14], and 


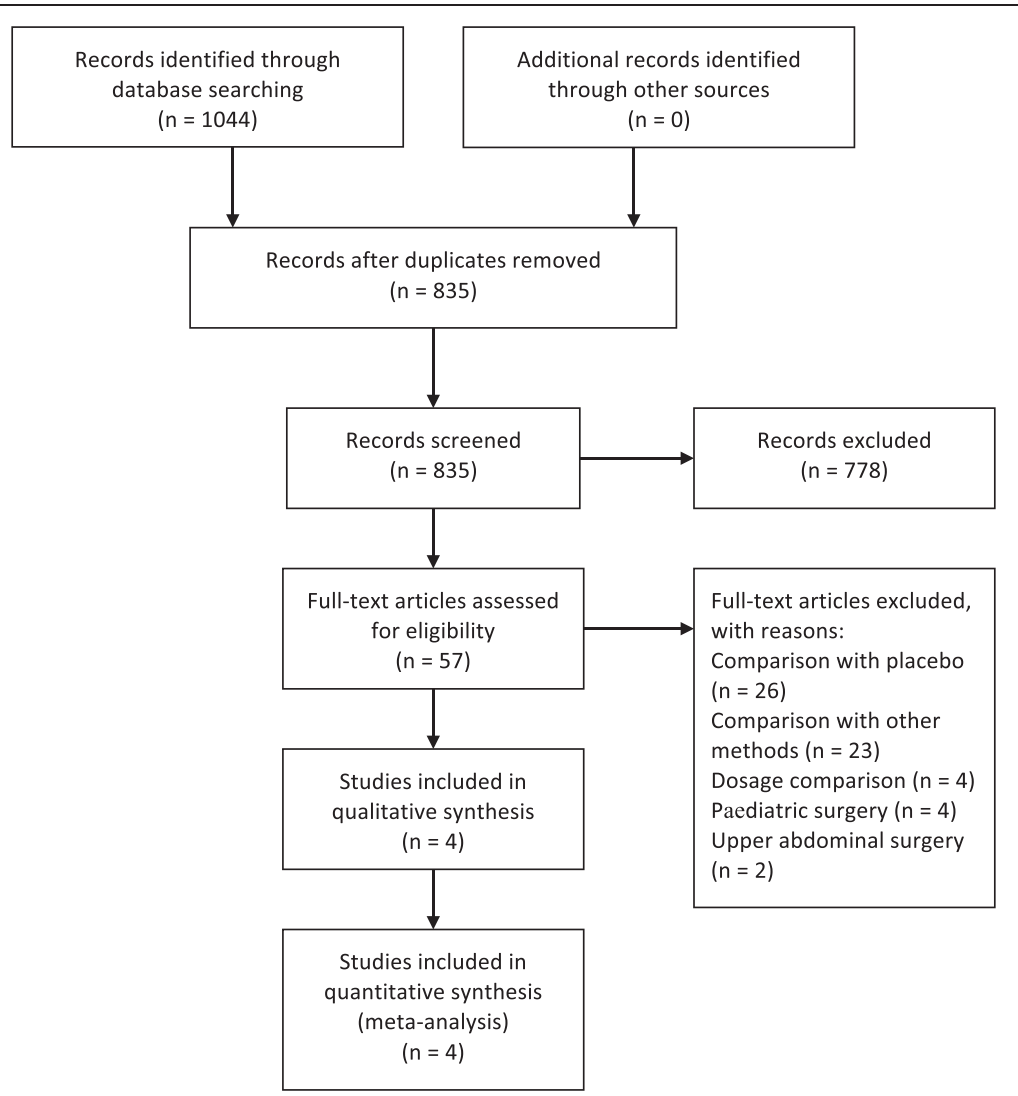

Figure 1 Study flow diagram.

pediatric $[15,16]$ surgeries, and it is suggested as part of the multimodal anesthetic approach to enhance recovery after lower abdominal surgeries [17].

Single shot local anesthetic infiltration (LAI) is also a commonly used method for reducing postoperative pain
$[18,19]$. Pain relief can be obtained by single injection of local anesthesia into skin and subcutaneous tissue layer at surgical incision sites, which could lower the pain scores until 24 hours postoperatively [20]. There have been a number of randomized controlled trials (RCTs)

Table 1 Characteristics of included studies

\begin{tabular}{|c|c|c|c|c|c|c|c|c|c|c|c|c|}
\hline \multirow[t]{2}{*}{ Author } & \multirow[t]{2}{*}{$\begin{array}{l}\text { Operation } \\
\text { performed }\end{array}$} & \multirow[t]{2}{*}{ Group } & \multirow[t]{2}{*}{$\mathbf{N}$} & \multirow[t]{2}{*}{ Anesthetic used } & \multicolumn{3}{|c|}{ VAS pain score at rest } & \multicolumn{3}{|c|}{$\begin{array}{l}\text { VAS pain score on } \\
\text { movement }\end{array}$} & \multirow{2}{*}{$\begin{array}{l}\text { Morphine } \\
\text { (mg) } \\
24 \mathrm{~h}\end{array}$} & \multirow{2}{*}{$\begin{array}{l}\text { PONV } \\
(\%) \\
24 \mathrm{~h}\end{array}$} \\
\hline & & & & & $2 \mathrm{~h}$ & $4 \mathrm{~h}$ & $24 \mathrm{~h}$ & $2 \mathrm{~h}$ & $4 \mathrm{~h}$ & $24 \mathrm{~h}$ & & \\
\hline \multirow[t]{2}{*}{ Atim 2011} & Hysterectomy & TAP & 18 & $\begin{array}{l}0.25 \% \text { bupivacaine, } \\
20 \mathrm{ml} \text { each side }\end{array}$ & $2.5 \pm 1.7$ & $2.0 \pm 2.1$ & $0.3 \pm 0.4$ & $2.8 \pm 1.7$ & $2.4 \pm 1.7$ & $0.3 \pm 0.4$ & & \\
\hline & & LAl & 19 & $\begin{array}{l}0.25 \% \text { bupivacaine, } \\
20 \mathrm{ml} \text { total }\end{array}$ & $3.7 \pm 2.2$ & $2.7 \pm 1.3$ & $1.0 \pm 0.9$ & $4.1 \pm 2.6$ & $2.8 \pm 1.3$ & $1.2 \pm 0.9$ & & \\
\hline \multirow[t]{2}{*}{ Sivapurapu 2013} & $\begin{array}{l}\text { Gynecological } \\
\text { surgery }\end{array}$ & TAP & 26 & $\begin{array}{l}0.25 \% \text { bupivacaine } \\
0.6 \mathrm{ml} / \mathrm{kg} \text {, total }\end{array}$ & $4.0 \pm 1.3$ & $3.6 \pm 0.8$ & $3.5 \pm 0.7$ & & & & $22.15 \pm 4.14$ & 4 \\
\hline & & LAl & 26 & $\begin{array}{l}0.25 \% \text { bupivacaine } \\
0.6 \mathrm{ml} / \mathrm{kg} \text {, total }\end{array}$ & $6.7 \pm 1.4$ & $5.1 \pm 0.7$ & $4.7 \pm 0.6$ & & & & $29.15 \pm 3.93$ & 23 \\
\hline \multirow[t]{2}{*}{ Petersen 2013} & $\begin{array}{l}\text { Inguinal hernia } \\
\text { repair }\end{array}$ & TAP & 29 & $\begin{array}{l}0.75 \% \text { ropivacaine, } \\
25 \mathrm{ml} \text { each side }\end{array}$ & $2.8 \pm 1.5$ & $3.1 \pm 1.8$ & $1.7 \pm 1.3$ & $4.3 \pm 1.8$ & $4.6 \pm 1.9$ & $3.7 \pm 1.8$ & $6.6 \pm 11.5$ & 17 \\
\hline & & LAI & 30 & $\begin{array}{l}0.375 \% \text { ropivacaine, } \\
40 \mathrm{ml} \text { total }\end{array}$ & $0.8 \pm 1.1$ & $1.2 \pm 1.3$ & $2.0 \pm 1.5$ & $1.3 \pm 1.6$ & $2.0 \pm 1.8$ & $4.5 \pm 2.3$ & $2.1 \pm 5.1$ & 20 \\
\hline \multirow[t]{2}{*}{ Skjelsager 2013} & $\begin{array}{l}\text { Open radical } \\
\text { prostatectomy }\end{array}$ & TAP & 23 & $\begin{array}{l}0.75 \% \text { ropivacaine, } \\
40 \mathrm{ml} \text { total }\end{array}$ & $1.8 \pm 1.6$ & $1.2 \pm 1.3$ & $0.6 \pm 1.0$ & $2.9 \pm 2.3$ & $2.8 \pm 2.2$ & $1.6 \pm 1.4$ & & 30 \\
\hline & & LAI & 25 & $\begin{array}{l}0.75 \% \text { ropivacaine, } \\
40 \mathrm{ml} \text { total }\end{array}$ & $2.0 \pm 1.5$ & $1.6 \pm 1.2$ & $0.9 \pm 0.8$ & $3.8 \pm 2.1$ & $3.3 \pm 1.8$ & $2.5 \pm 1.9$ & & 25 \\
\hline
\end{tabular}


Table 2 Modified quality score for randomized trialst

\begin{tabular}{|c|c|c|c|c|}
\hline Quality variables & Atim 2011 & Sivapurapu 2013 & Petersen 2013 & Skjelsager 2013 \\
\hline $\begin{array}{l}\text { Was study described as randomized, ie, used words such as "randomly", } \\
\text { "random", and "randomization"? [0,1] }\end{array}$ & 1 & 1 & 1 & 1 \\
\hline Was randomization described, and appropriate? $[-1,0,1]$ & 1 & 1 & 1 & 1 \\
\hline Was study described as double-blinded? $[0,1]$ & 1 & 0 & 1 & 1 \\
\hline Was method of blinding appropriate? $[-1,0,1]$ & 1 & 1 & 1 & 1 \\
\hline Was a description of withdrawals and dropouts included? $[0,1]$ & 1 & 0 & 1 & 1 \\
\hline Inclusion criteria & 1 & 1 & 1 & 1 \\
\hline Exclusion criteria & 1 & 1 & 1 & 1 \\
\hline Study period given & 0 & 0 & 1 & 1 \\
\hline Appropriate statistical analysis & 1 & 1 & 1 & 1 \\
\hline Hard end points & 1 & 1 & 1 & 1 \\
\hline Sample size calculation & 1 & 1 & 1 & 1 \\
\hline Baseline characteristics comparable & 1 & 1 & 1 & 1 \\
\hline Any postoperative data missing? & 1 & 1 & 1 & 1 \\
\hline Allocation concealment & 1 & 0 & 1 & 1 \\
\hline Analysis by intention to treat & 0 & 0 & 0 & 0 \\
\hline Score $^{\ddagger}$ & 13 & 10 & 14 & 14 \\
\hline
\end{tabular}

${ }^{+}$Score maximum $=15$. Poor $=-1$ to 5 , Fair $=6$ to 10, Good $=11$ to 15 .

$\neq_{-1}=$ inappropriate or inaccurate, $0=$ not given/inadequate information, $1=$ described and accurate.

comparing the efficacy of TAP block to that of LAI, but the results are inconsistent. Thus, we conducted a metaanalysis of all RCTs in this area to determine whether TAP block is more efficacious during the postoperative period of lower abdominal surgery in adults.

\section{Methods}

\section{Study identification}

A comprehensive literature search was performed using the following search terms: transvers abdominis plane block or transverse abdominis plane block or TAP block. No limitations with respect to sex, human or animal studies, language, or publication year were applied. The search was performed independently by two authors (N. Y. and X. L.) according to the validated methods of the PRISMA statement [21]. The databases, searched prior to 1 January 2014, were PubMed (1966-2014), MEDLINE ${ }^{\bullet}$ (1966-2014),
EMBASE (1974-2014), Cochrane Central Register of Controlled Trials (1996-2014), and Cumulative Index to Nursing and Allied Health Literature (CINAHL) (1983-2014). Unpublished trials and conference proceedings were searched with the System for Information on Grey Literature in Europe, the National Research Register (UK), and trial registries. Papers were also searched among those quoted as references in the retrieved studies to ensure the relevant studies were included and the language was limited to English only.

\section{Study selection}

Articles were included if they met the following criteria:

- Study design: RCT

- Population: Human adults (18 years old and older) who underwent lower abdominal surgery

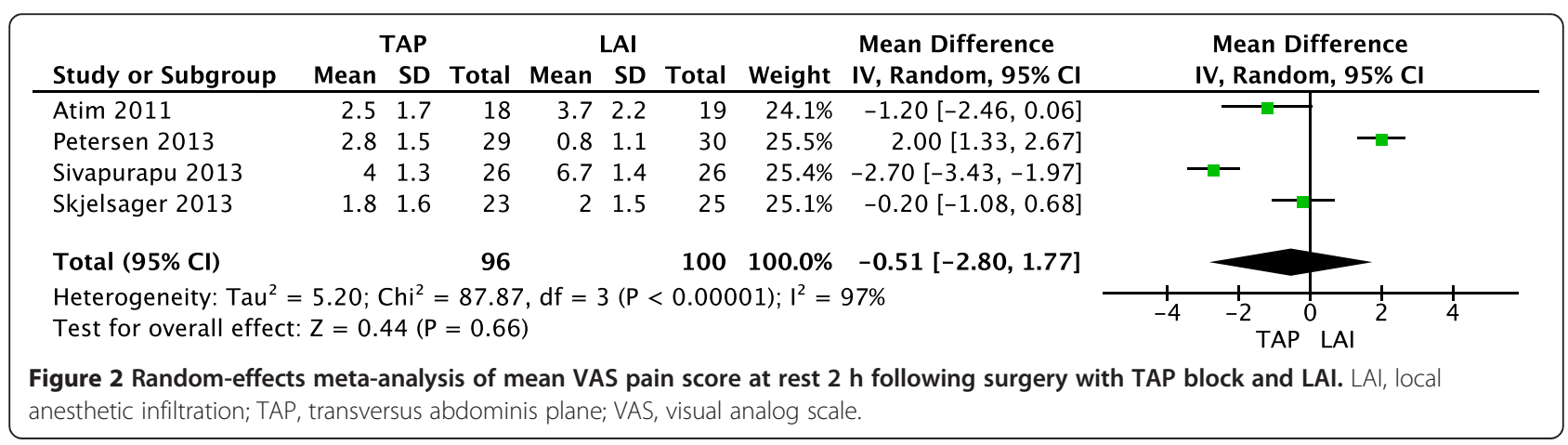




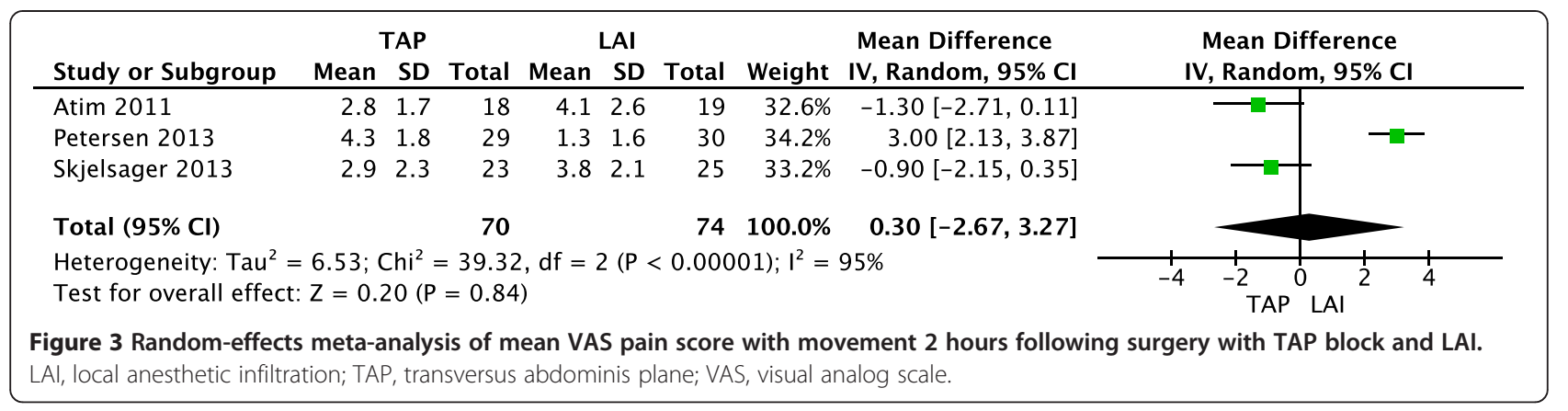

- Intervention: single-shot TAP block compared with single-shot LAI

- Outcomes:
1. Efficacy (postoperative pain at rest/with movement);
2. Postoperative morphine requirement;
3. Postoperative nausea and vomiting (PONV)

Exclusion criteria were as follows:

- Non-randomized studies

- TAP block compared with placebo or other methods, or TAP-block dosage comparison

- Studies involving preperitoneal injection

- Pediatric surgery

- Letters, case reports, reviews, comments, and editorials

- Languages other than English

- Animal studies

Studies were considered for inclusion independently by two authors (N. Y. and X. L.) and any disagreements were resolved by consensus after consultation with a senior author (X.W.) (Figure 1). Each article was critically reviewed for eligibility in our analysis.

\section{Data extraction}

A table was designed to include the most relevant variables common to the papers assessed (Table 1). The outcomes of interest were postoperative VAS pain scores, morphine requirements, and rates of PONV. Two authors (N. Y. and X. L.) independently extracted data from eligible articles and any discrepancy was resolved prior to final analysis. Missing information and inadequate data were sought from corresponding authors through email correspondence over a period of 2 months, and if there was no response, the data were considered incomplete.

\section{Statistical analysis}

Data analysis was performed with Revman 5.2 (The Cochrane Collaboration, Copenhagen, Denmark) and Stata Statistical Software, Release 9 (StataCorp. LP, College Station, TX, USA). For continuous data, Hedges' g statistic was used to calculate weighted mean difference (WMD) and 95\% confidence interval (CI). Inverse variance was used for continuous outcome variables. Binary data was summarized as risk ratios (RR) and 95\% CI. The heterogeneity of the estimators was tested using $\mathrm{I}^{2}$. When $\mathrm{I}^{2}$ was lower than $50 \%$, the studies were considered to have acceptable heterogeneity and the fixed-effect model with Mantel-Haenszel method was then used; otherwise, a random-effects model with the DerSimonian and Laird (DL) method was adopted. Forest plots were constructed. The pooled effect and its 95\% CI were represented by a diamond that did not cross the vertical line of no effect (standard error of mean difference $[\mathrm{SMD}]=0)$, and $\mathrm{P}<0.05$ was considered to be statistically significant.

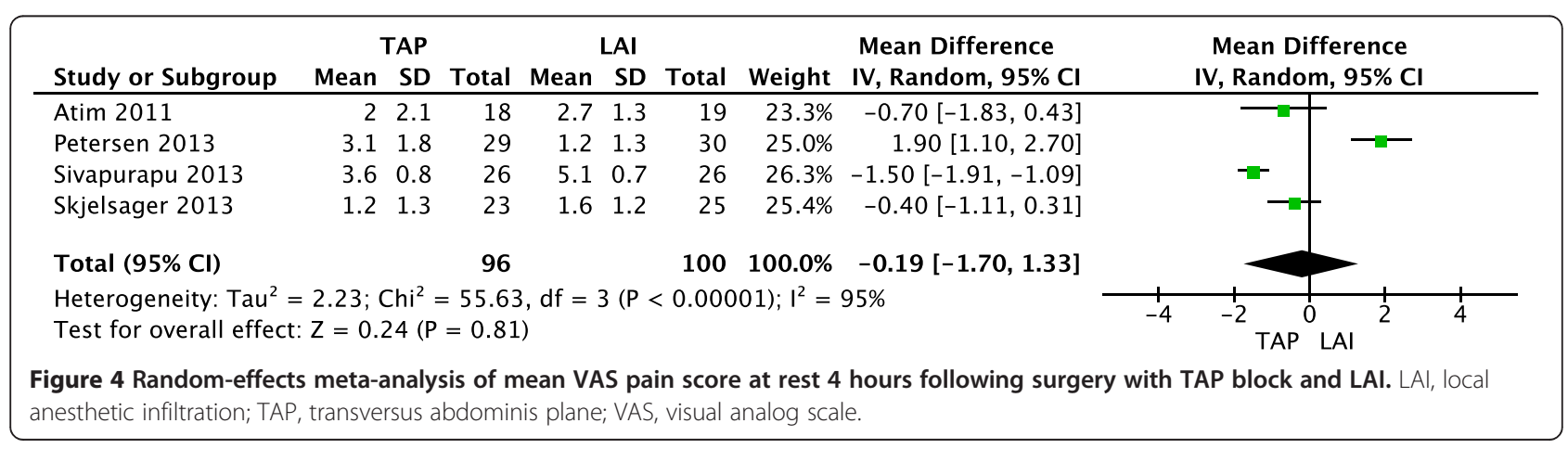




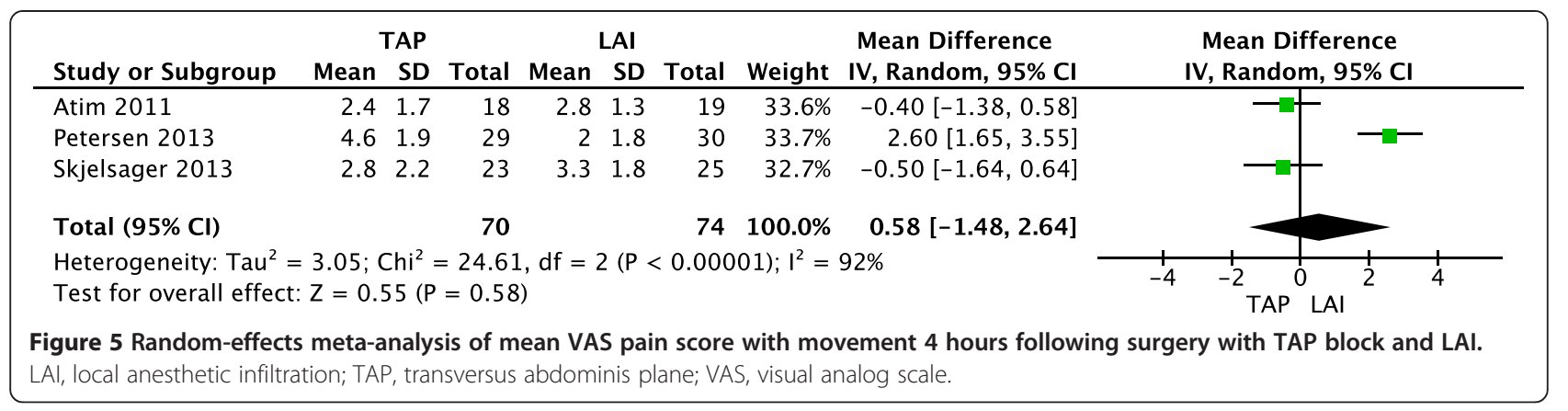

Potential publication bias was investigated with funnel plot of the SMD against the mean difference of the study, which was used as the main graphical method. To supplement the funnel-plot approach, Egger linear regression was used to test for publication bias using quantitative analysis.

\section{Results}

The database search produced 1044 studies, of which four were eligible for analysis after applying exclusion criteria $[8-10,12]$. The quality of the included studies was assessed with a combined-criteria score system, as set out by Jadad et al. [22] and Chalmers et al. [23] (Table 2). Totally there were 96 patients of the TAP-block group and 100 of the LAI group included in this study. We deleted a single study from the overall pooled analysis each time to check sensitivity; the result did not significantly affect the overall estimate.

\section{VAS scores at 2 hours postoperation}

Four studies [8-10,12] (196 patients; 96 TAP block, 100 LAI) reported VAS scores at rest $2 \mathrm{~h}$ after surgery. There was significant heterogeneity among the studies $\left(\mathrm{I}^{2}=97 \%\right.$, $\mathrm{P}<0.00001$ ). A random-effects model was used, there was no significant difference in mean VAS pain score $2 \mathrm{~h}$ postoperatively between patients who received LAI and those with TAP block (Figure 2).

Three studies [8,9,12] (144 patients; 70 TAP block, 74 LAI) reported VAS scores with movement $2 \mathrm{~h}$ after surgery. There was significant heterogeneity among the studies $\left(\mathrm{I}^{2}=95 \%, \mathrm{P}<0.00001\right)$. A random-effects model was used, there was no significant difference in mean VAS pain score $2 \mathrm{~h}$ postoperatively between patients who received LAI and those with TAP block (Figure 3).

\section{VAS scores at $\mathbf{4}$ hours postoperation}

Four studies [8-10,12] (196 patients; 96 TAP block, 100 LAI) reported VAS scores at rest $4 \mathrm{~h}$ after surgery. There was significant heterogeneity among the studies $\left(\mathrm{I}^{2}=95 \%\right.$, $\mathrm{P}<0.00001$ ). A random-effects model was used, and there was no significant difference in mean VAS pain score $4 \mathrm{~h}$ postoperatively between patients who received LAI and those with TAP block (Figure 4).

Three studies [8,9,12] (144 patients; 70 TAP block, 74 local infiltration) reported VAS scores with movement at $4 \mathrm{~h}$ after surgery. There was significant heterogeneity among the studies $\left(\mathrm{I}^{2}=92 \%, \mathrm{P}<0.00001\right)$. A random-effects model was used, and there was no significant difference in mean VAS pain score at $4 \mathrm{~h}$ between patients who had received LAI and those who had received TAP block (Figure 5).

\section{VAS scores after 24 hours postoperation}

Four studies [8-10,12] (196 patients; 96 TAP block, 100 LAI) reported VAS scores at rest $24 \mathrm{~h}$ after surgery. There was significant heterogeneity among the studies $\left(\mathrm{I}^{2}=72 \%, \mathrm{P}=0.01\right)$. A random-effects model was used, and there was significant reduction in mean VAS pain score at $24 \mathrm{~h}$ postoperation in patients received TAP block compared with those who had LAI (Figure 6).

Three studies [8,9,12] (144 patients; 70 TAP block, 74 LAI) reported VAS scores with movement $24 \mathrm{~h}$ after

\begin{tabular}{|c|c|c|c|c|c|c|c|c|c|c|}
\hline Study or Subgroup & \multicolumn{3}{|c|}{ TAP } & \multicolumn{3}{|c|}{ LAI } & Weight & $\begin{array}{l}\text { Mean Difference } \\
\text { IV, Random, } 95 \% \mathrm{CI}\end{array}$ & \multicolumn{2}{|c|}{$\begin{array}{c}\text { Mean Difference } \\
\text { IV, Random, } 95 \% \mathrm{Cl}\end{array}$} \\
\hline Atim 2011 & 0.3 & 0.4 & 18 & 1 & 0.9 & 19 & $26.8 \%$ & $-0.70[-1.14,-0.26]$ & - & \\
\hline Petersen 2013 & 1.7 & 1.3 & 29 & 2 & 1.5 & 30 & $19.1 \%$ & $-0.30[-1.02,0.42]$ & & \\
\hline Sivapurapu 2013 & 3.5 & 0.7 & 26 & 4.7 & 0.6 & 26 & $29.5 \%$ & $-1.20[-1.55,-0.85]$ & $-\square$ & \\
\hline Skjelsager 2013 & 0.6 & 1 & 23 & 0.9 & 0.8 & 25 & $24.6 \%$ & $-0.30[-0.82,0.22]$ & $一-$ & - \\
\hline Total $(95 \% \mathrm{Cl})$ & & & 96 & & & 100 & $100.0 \%$ & $-0.67[-1.13,-0.22]$ & & \\
\hline \multicolumn{9}{|c|}{$\begin{array}{l}\text { Heterogeneity: } \mathrm{Tau}^{2}=0.15 ; \mathrm{Chi}^{2}=10.58, \mathrm{df}=3(\mathrm{P}=0.01) ; \mathrm{I}^{2}=72 \% \\
\text { Test for overall effect: } \mathrm{Z}=2.89(\mathrm{P}=0.004)\end{array}$} & $\begin{array}{ccc} & 1 & 1 \\
-2 & -1 & 0\end{array}$ & 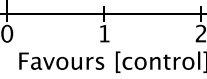 \\
\hline
\end{tabular}




\begin{tabular}{|c|c|c|c|c|c|c|c|c|c|c|c|c|}
\hline \multirow[b]{2}{*}{ Study or Subgroup } & \multicolumn{3}{|c|}{ TAP } & \multicolumn{3}{|c|}{ LAI } & \multicolumn{3}{|c|}{ Mean Difference } & \multirow{2}{*}{\multicolumn{3}{|c|}{$\begin{array}{l}\text { Mean Difference } \\
\text { IV, Fixed, } 95 \% \mathrm{Cl}\end{array}$}} \\
\hline & Mean & SD & Total & Mean & SD & Total & Weight & IV, Fixed, 95\% CI & & & & \\
\hline Atim 2011 & 0.3 & 0.4 & 18 & 1.2 & 0.9 & 19 & $71.3 \%$ & $-0.90[-1.34,-0.46]$ & & -- & & \\
\hline Petersen 2013 & 3.7 & 1.8 & 29 & 4.5 & 2.3 & 30 & $12.7 \%$ & $-0.80[-1.85,0.25]$ & & & - & \\
\hline Skjelsager 2013 & 1.6 & 1.4 & 23 & 2.5 & 1.9 & 25 & $16.0 \%$ & $-0.90[-1.84,0.04]$ & & & & \\
\hline Total $(95 \% \mathrm{Cl})$ & & & 70 & & & 74 & $100.0 \%$ & $-0.89[-1.26,-0.51]$ & & & & \\
\hline \multicolumn{9}{|c|}{$\begin{array}{l}\text { Heterogeneity: } \mathrm{Chi}^{2}=0.03, \mathrm{df}=2(P=0.98) ; I^{2}=0 \% \\
\text { Test for overall effect: } Z=4.63(P<0.00001)\end{array}$} & -2 & -1 TA & $0_{\text {LAI }}^{1} 1$ & $\frac{1}{2}$ \\
\hline
\end{tabular}

surgery. There was no significant heterogeneity among the studies $\left(\mathrm{I}^{2}=0 \%, \mathrm{P}=0.98\right)$. A fixed-effects model was used, and there was significant reduction in mean VAS pain score at $24 \mathrm{~h}$ postoperation in patients received TAP block compared with those who had LAI (Figure 7).

\section{Morphine requirements after $\mathbf{2 4}$ hours postoperation}

Two studies [8,10] (114 patients; 55 TAP block, 56 LAI) reported morphine requirements (mg) $24 \mathrm{~h}$ after surgery. There was significant heterogeneity among the studies $\left(\mathrm{I}^{2}=95 \%, \mathrm{P}<0.00001\right)$. A random-effects model was used, and there was no significant difference in mean morphine requirements at $24 \mathrm{~h}$ between patients received TAP block and those with LAI (Figure 8).

\section{PONV rate at 24 hours}

Three studies [8,10,12] (159 patients; 78 TAP block, 81 LAI) reported rate of PONV at $24 \mathrm{~h}$ after surgery. There was no significant heterogeneity among the studies $\left(\mathrm{I}^{2}=40 \%\right.$, $\mathrm{P}=0.19$ ). A fixed-effects model was used, and there was no significant difference in mean rate of PONV at $24 \mathrm{~h}$ between the TAP group and LAI group (Figure 9).

\section{Risk of bias and publication bias}

Overall, the included RCTs were of moderate to high quality, as shown in Additional file 1: Figures S1-S10. Funnel plots are also shown in the Additional file 1: Figures S1-S10. However, Egger's linear regression revealed no evidence of publication bias in this metaanalysis $(\mathrm{P}=0.625)$.

\section{Discussion}

Postoperative pain management is one of the main concerns of both the surgeons and theirs patients. Multiple methods have been put into use to achieve the ideal of pain-free recovery such as LAI [20], epidural analgesia [24], peripheral nerve block [25], and intravenous patient-controlled analgesia [26]. TAP block, which can be easily performed under ultrasound guidance [27] or using a landmark-based approach [28,29], is becoming more and more commonly applied in lower abdominal surgeries to decrease postoperative pain. TAP block is currently described as an effective technique for reducing postoperative pain and morphine consumption after lower abdominal surgery [17,30,31]. Meanwhile, LAI is a convenient postoperative analgesia method, which have been widely performed. Thus it would be helpful to figure out which technique will be more effective in postoperative pain control. To the best of our knowledge, this is the first meta-analysis that has been performed on this topic.

Postoperative pain alleviation is our primary outcome. VAS pain score, considered the gold standard of pain quantification [32], was used to evaluate postoperative pain severity on a scale of 1 to 10 in all the included studies, both at rest and with movement. Our review found that there was a significantly lower pain score in the TAP group at 24 hours postoperatively. However, no significant difference was detected at any other time point, which suggests that TAP block is effective for relatively long-lasting analgesia. LAI is limited to a short period of pain control, and the effect reaches the peak at $1 \mathrm{~h}$ postoperatively; then the effect decreases to the

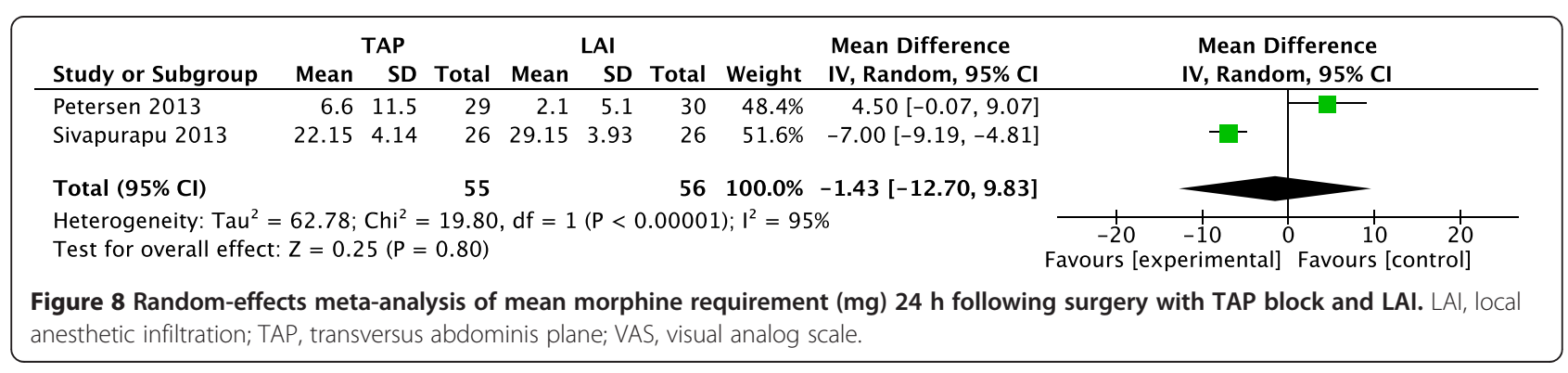




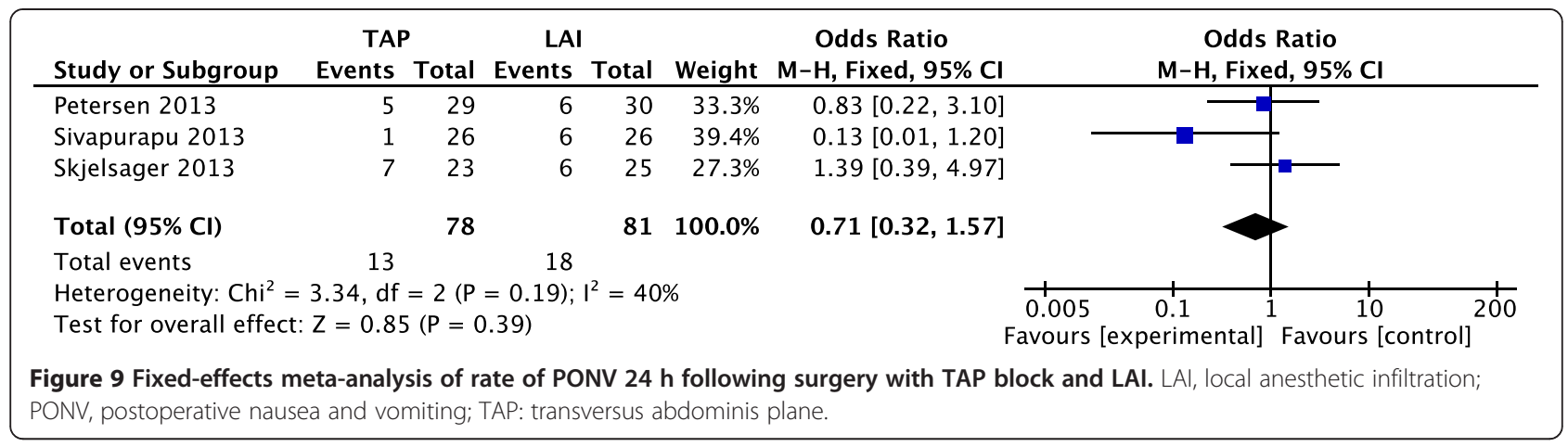

minimum by $8 \mathrm{~h}$, and is negligible at $16 \mathrm{~h}$ [33]. While TAP block demonstrates its advantage gradually over time. The results of this study are consistent with the observations reported by Ortiz and other researchers [34] that the efficacy of TAP is of longer duration than that of LAI. However, it should be noted that the improvement in pain scores differed by less than one point between TAP AND LAI groups, both at rest and with movement 24 hours after surgery. It suggests that even though it is statistically significant, the two methods may not be clinically significant as it may be challenging for a patient to tell the difference between a VAS score of 2 and 3. In addition, in patients with VAS scores less than 3.4 , a mean change of 1.3 could be considered as clinically significant [35]. Therefore it is still uncertain that TAP provides better long-lasting clinical results.

Reducing of postoperative morphine requirement and associated side effects are also desirable, as these are considered detrimental to patient's recovery [36]. TAP block is effective in reducing both $24 \mathrm{~h}$ postoperative morphine requirements and PONV compared with placebo [17]; meanwhile other studies have shown that LAI also decreases postoperative opiate requirements [37] and nausea and vomiting [17] compared with placebo. Data analyzed in this study demonstrated that TAP block did not significantly reduce morphine requirements or PONV compared with LAI $24 \mathrm{~h}$ after surgery, suggesting that both methods have good postoperative analgesic effect.

No complication was reported in the included studies. However, TAP block has complications including block failure, vascular injury, abdominal viscera and nerve injuries [38]. Ultrasound-guided TAP block, which allows more accurate visualization of the needle, TAP plane, and injection spot, is considered to be safer clinically.

Our meta-analysis is limited by the small sample size of included studies and by the significant heterogeneity of the outcomes. There were only four studies, totally 196 patients included. During data collection, all the authors of the studies included were emailed three times over a period of 2 months to require the raw data for further assessment and reducing bias, but few of them responded. The heterogeneity is related with different types of surgeries performed and the type and dose of analgesia (which will affect the efficacy and duration of block). Further limitations include differences in block technique and timing of administration.

Our review findings raise another important clinical question regarding time and cost. LAI, performed under direct visualization, is simple and quick; ultrasound-guided TAP block is operator-dependent and time-consuming; thus, future research are required to demonstrate the time requirements and cost efficiency of these two methods.

\section{Conclusions}

TAP block is comparable to LAI for short-term analgesia; it could also provide better long-lasting analgesia especially at $24 \mathrm{~h}$ after surgery. Current evidence is insufficient to conclude that TAP block could reduce the requirements for postoperative morphine and associated side effects as compared to LAI. Further RCTs should be performed to figure out the different benefit of these two methods.

\section{Additional file}

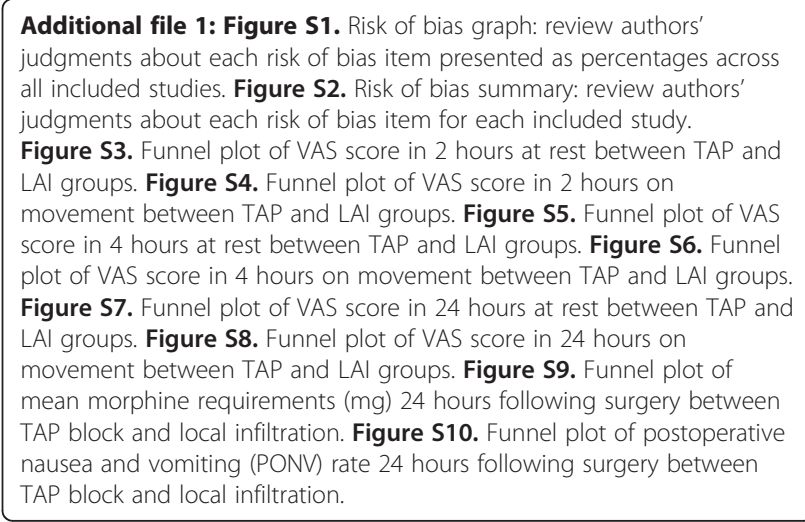

Abbreviations

LAI: Local anesthetic infiltration; PONV: Postoperative nausea and vomiting; RCT: Randomized controlled trial; TAP: Transversus abdominis plane; VAS: Visual analog scale. 


\section{Competing interests}

The authors declare that they have no competing interests. The authors have no support or funding to report.

\section{Authors' contributions}

NY: Conception and design, collection and assembly of data, data analysis and interpretation, manuscript writing; XL: Conception and design, collection and assembly of data, data analysis and interpretation, manuscript writing; JRL-H: Data analysis and interpretation, manuscript writing; JS: Data analysis and interpretation, manuscript writing; XX: Conception and design, manuscript writing; XW: Conception and design, data analysis and interpretation, manuscript writing, final approval of manuscript. All authors read and approved the final manuscript.

\section{Acknowledgements}

The assistance of the Center for Clinical Investigation of Brigham and Women's Hospital, Harvard Medical School, Boston, MA, is gratefully acknowledged.

\section{Author details}

${ }^{1}$ Division of Plastic Surgery, Peking Union Medical College Hospital, Peking Union Medical College, Chinese Academy of Medical Science, No.1 Shuaifuyuan, Wangfujing, Dongcheng District, Beijing 100730, China 2Division of Plastic Surgery, Brigham and Women's Hospital and Harvard Medical School, Boston, MA, USA. ${ }^{3}$ Department of Surgery, University of Kentucky, Lexington, KY, USA. ${ }^{4}$ Department of Anesthesiology, Peking Union Medical College Hospital, Peking Union Medical College, Chinese Academy of Medical Science, Beijing, China.

Received: 22 March 2014 Accepted: 11 December 2014 Published: 15 December 2014

\section{References}

1. Schug SA: 2011-the global year against acute pain. Anaesth Intensive Care 2011, 39(1):11-14.

2. Liu SS, Wu CL: Effect of postoperative analgesia on major postoperative complications: a systematic update of the evidence. Anesth Analg 2007, 104(3):689-702.

3. Mhuircheartaigh RJ, Moore RA, McQuay HJ: Analysis of individual patient data from clinical trials: epidural morphine for postoperative pain. Br J Anaesth 2009, 103(6):874-881.

4. Kuppuvelumani $P$, Jaradi $H$, Delilkan A: Abdominal nerve blockade for postoperative analgesia after caesarean section. Asia Oceania J Obstet Gynaecol 1993, 19(2):165-169.

5. Rafi AN: Abdominal field block: a new approach via the lumbar triangle. Anaesthesia 2001, 56(10):1024-1026.

6. Aveline C, Le Hetet H, Le Roux A, Vautier P, Cognet F, Vinet E, Tison C, Bonnet F: Comparison between ultrasound-guided transversus abdominis plane and conventional ilioinguinal/iliohypogastric nerve blocks for day-case open inguinal hernia repair. Br J Anaesth 2011, 106(3):380-386.

7. Albrecht E, Kirkham KR, Endersby RV, Chan WW, Jackson T, Okrainec A, Penner T, Jin R, Brull R: Ultrasound-guided Transversus Abdominis Plane (TAP) block for laparoscopic gastric-bypass surgery:a prospective randomized controlled double-blinded trial. Obes Surg 2013, 23(8):1309-1314.

8. Petersen PL, Mathiesen O, Stjernholm P, Kristiansen VB, Torup H, Hansen EG, Mitchell AU, Moeller A, Rosenberg J, Dahl JB: The effect of transversus abdominis plane block or local anaesthetic infiltration in inguinal hernia repair: a randomised clinical trial. Eur J Anaesthesiol 2013, 30(7):415-421.

9. Atim A, Bilgin F, Kilickaya O, Purtuloglu T, Alanbay I, Orhan ME, Kurt E: The efficacy of ultrasound-guided transversus abdominis plane block in patients undergoing hysterectomy. Anaesth Intensive Care 2011, 39(4):630-634

10. Sivapurapu V, Vasudevan A, Gupta S, Badhe AS: Comparison of analgesic efficacy of transversus abdominis plane block with direct infiltration of local anesthetic into surgical incision in lower abdominal gynecological surgeries. J Anaesthesiol Clin Pharmacol 2013, 29(1):71-75.

11. Belavy D, Cowlishaw PJ, Howes M, Phillips F: Ultrasound-guided transversus abdominis plane block for analgesia after Caesarean delivery. Br J Anaesth 2009, 103(5):726-730.

12. Skjelsager A, Ruhnau B, Kistorp TK, Kridina I, Hvarness H, Mathiesen O, Dahl JB: Transversus abdominis plane block or subcutaneous wound infiltration after open radical prostatectomy: a randomized study. Acta Anaesthesiol Scand 2013, 57(4):502-508

13. Araco A, Pooney J, Araco F, Gravante G: Transversus abdominis plane block reduces the analgesic requirements after abdominoplasty with flank liposuction. Ann Plast Surg 2010, 65(4):385-388.

14. Sforza M, Andjelkov K, Zaccheddu R, Nagi H, Colic M: Transversus abdominis plane block anesthesia in abdominoplasties. Plast Reconstr Surg 2011, 128(2):529-535.

15. Sahin L, Sahin M, Gul R, Saricicek V, Isikay N: Ultrasound-guided transversus abdominis plane block in children: a randomised comparison with wound infiltration. Eur J Anaesthesiol 2013, 30(7):409-414.

16. Sandeman DJ, Bennett M, Dilley AV, Perczuk A, Lim S, Kelly KJ: Ultrasoundguided transversus abdominis plane blocks for laparoscopic appendicectomy in children: a prospective randomized trial. $\mathrm{Br} J$ Anaesth 2011, 106(6):882-886.

17. Johns N, O'Neill S, Ventham NT, Barron F, Brady RR, Daniel T: Clinical effectiveness of Transversus Abdominis Plane (TAP) block in abdominal surgery: a systematic review and meta-analysis. Colorectal Dis 2012, 14(10):e635-e642.

18. Coughlin SM, Karanicolas PJ, Emmerton-Coughlin HM, Kanbur B, Kanbur S, Colquhoun PH: Better late than never? Impact of local analgesia timing on postoperative pain in laparoscopic surgery: a systematic review and metaanalysis. Surg Endosc 2010, 24(12):3167-3176.

19. Einarsson Jl, Sun J, Orav J, Young AE: Local analgesia in laparoscopy: a randomized trial. Obstet Gynecol 2004, 104(6):1335-1339.

20. Gupta A: Local anaesthesia for pain relief after laparoscopic cholecystectomy-a systematic review. Best Pract Res Clin Anaesthesiol 2005, 19(2):275-292.

21. Moher D, Liberati A, Tetzlaff J, Altman DG, Group P: Preferred reporting items for systematic reviews and meta-analyses: the PRISMA statement BMJ 2009, 339:b2535.

22. Jadad AR, Moore RA, Carroll D, Jenkinson C, Reynolds DJ, Gavaghan DJ, McQuay HJ: Assessing the quality of reports of randomized clinical trials: is blinding necessary? Control Clin Trials 1996, 17(1):1-12.

23. Chalmers TC, Smith H Jr, Blackburn B, Silverman B, Schroeder B, Reitman D, Ambroz A: A method for assessing the quality of a randomized control trial. Control Clin Trials 1981, 2(1):31-49.

24. Ventham NT, Hughes M, O'Neill S, Johns N, Brady RR, Wigmore SJ: Systematic review and meta-analysis of continuous local anaesthetic wound infiltration versus epidural analgesia for postoperative pain following abdominal surgery. Br J Anaesth 2013, 100(10):1280-1289.

25. Fowler SJ, Christelis N: High volume local infiltration analgesia compared to peripheral nerve block for hip and knee arthroplasty-what is the evidence? Anaesth Intensive Care 2013, 41(4):458-462.

26. Gousheh SM, Nesioonpour S, Javaher Foroosh F, Akhondzadeh R, Sahafi SA, Alizadeh Z: Intravenous paracetamol for postoperative analgesia in laparoscopic cholecystectomy. Anesth Pain Med 2013, 3(1):214-218.

27. El-Dawlatly AA, Turkistani A, Kettner SC, Machata AM, Delvi MB, Thallaj A Kapral S, Marhofer P: Ultrasound-guided transversus abdominis plane block: description of a new technique and comparison with conventional systemic analgesia during laparoscopic cholecystectomy. Br J Anaesth 2009, 102(6):763-767.

28. Petersen PL, Stjernholm P, Kristiansen VB, Torup H, Hansen EG, Mitchell AU, Moeller A, Rosenberg J, Dahl JB, Mathiesen O: The beneficial effect of transversus abdominis plane block after laparoscopic cholecystectomy in day-case surgery: a randomized clinical trial. Anesth Analg 2012, 115(3):527-533.

29. Salman AE, Yetisir F, Yurekli B, Aksoy M, Yildirim M, Kilic M: The efficacy of the semi-blind approach of transversus abdominis plane block on postoperative analgesia in patients undergoing inguinal hernia repair: a prospective randomized double-blind study. Local Reg Anesth 2013, 6:1-7.

30. Abdallah FW, Halpern SH, Margarido CB: Transversus abdominis plane block for postoperative analgesia after Caesarean delivery performed under spinal anaesthesia? A systematic review and meta-analysis. Br J Anaesth 2012, 109(5):679-687.

31. Siddiqui MR, Sajid MS, Uncles DR, Cheek L, Baig MK: A meta-analysis on the clinical effectiveness of transversus abdominis plane block. J Clin Anesth 2011, 23(1):7-14.

32. Myles PS, Urquhart N: The linearity of the visual analogue scale in patients with severe acute pain. Anaesth Intensive Care 2005, 33(1):54-58

33. Ayman M, Materazzi G, Bericotti M, Rago R, Nidal Y, Miccoli P: Bupivacaine $0.5 \%$ versus ropivacaine $0.75 \%$ wound infiltration to decrease 
postoperative pain in total thyroidectomy, a prospective controlled study. Minerva Chir 2012, 67(6):511-516.

34. Ortiz J, Suliburk JW, Wu K, Bailard NS, Mason C, Minard CG, Palvadi RR: Bilateral transversus abdominis plane block does not decrease postoperative pain after laparoscopic cholecystectomy when compared with local anesthetic infiltration of trocar insertion sites. Reg Anesth Pain Med 2012, 37(2):188-192.

35. Bird SB, Dickson EW: Clinically significant changes in pain along the visual analog scale. Ann Emerg Med 2001, 38(6):639-643.

36. Jorgensen H, Wetterslev J, Moiniche S, Dahl JB: Epidural local anaesthetics versus opioid-based analgesic regimens on postoperative gastrointestinal paralysis, PONV and pain after abdominal surgery. Cochrane Database Syst Rev 2000, (4):CD001893.

37. Gupta A, Favaios S, Perniola A, Magnuson A, Berggren L: A meta-analysis of the efficacy of wound catheters for post-operative pain management. Acta Anaesthesiol Scand 2011, 55(7):785-796.

38. Soltani Mohammadi S, Dabir A, Shoeibi G: Efficacy of transversus abdominis plane block for acute postoperative pain relief in kidney recipients: a double-blinded clinical trial. Pain Med 2014, 15(3):460-464.

doi:10.1186/1471-2253-14-121

Cite this article as: Yu et al.: Transversus abdominis-plane block versus local anesthetic wound infiltration in lower abdominal surgery: a systematic review and meta-analysis of randomized controlled trials. BMC Anesthesiology 2014 14:121.

\section{Submit your next manuscript to BioMed Central and take full advantage of:}

- Convenient online submission

- Thorough peer review

- No space constraints or color figure charges

- Immediate publication on acceptance

- Inclusion in PubMed, CAS, Scopus and Google Scholar

- Research which is freely available for redistribution 